\title{
METABOLIC STUDIES WITH A NEW SERIES OF 1,4-DIENE STEROIDS. I. EFFECTS IN ADDISONIAN SUBJECTS OF PREDNISONE, PRED- NISOLONE, AND THE 1,2-DEHYDRO ANALOGUES OF COR- TICOSTERONE, DESOXYCORTICOSTERONE, 17- HYDROXY-11-DESOXYCORTICOSTERONE, AND $9 \alpha-$ FLUOROCORTISOL *
}

\author{
By MAURICE M. PECHET $\dagger$ BLAIR BOWERS $\ddagger$ AND FREDERIC C. BARTTER \\ (From the Clinic of General Medicine and Experimental Therapeutics, National Heart Institute, \\ National Institutes of Health, Bethesda, Md.)
}

(Submitted for publication May 13, 1958; accepted December 4, 1958)

Prednisone and prednisolone, ${ }^{1}$ the first steroids in this series (2), were shown to possess antiinflammatory activities much greater than those of the parent steroids, cortisone and cortisol (3). The present study was undertaken to delineate further the change in physiologic function resulting from the introduction of the extra double bond. A number of later reports of the metabolic effects of three of these steroids are now available $(4-6)$.

\section{METHODS}

Balance studies were carried out on three female patients with Addison's disease. In all patients the diagnosis had been established clinically, and confirmed by the findings of control 17-ketosteroids and 17-hydroxycorticoid excretion of less than $1 \mathrm{mg}$. per day, not rising with adrenocorticotropic hormone (ACTH). Each had been maintained in good clinical condition with oral cortisone and daily intramuscular desoxycorticosterone injections until eight to 10 days before the first steroid was given in these studies. No further supportive treatment was given. The diet and fliud intake were kept constant throughout each study. A liquid diet was used throughout the study on L. M. B. and in one study on A. M. B. Stools were

* Part of this material has been presented previously (1). The names "metacortandracin" and "metacortandralone" have since been replaced by "prednisone" and "prednisolone."

$\dagger$ Present address: Medical Service, Massachusetts General Hospital, Boston, Mass.

$\ddagger$ Present address: Harvard University, Cambridge, Mass.

1 The trivial names, together with the chemical names, of the steroids studied are as follows: prednisone, $17 \alpha, 21$ dihydroxypregna -1,4-diene-3,11,20-trione; prednisolone, $11 \beta, 17 \alpha, 21$-trihydroxypregna-1,4-diene-3,20-dione ; cortisone, 17 $\alpha, 21$-dihydroxypregn-4-ene-3,11,20-trione ; cortisol, $11 \beta, 17 \alpha, 21$-trihydroxypregn-4-ene-3,20-dione ; desoxycorticosterone, 21-hydroxypregn-4-ene-3,20-dione; $9 \alpha$-fluoroprednisolone, $9 \alpha$-fluoro, $11 \beta, 17 \alpha, 21$ - trihydroxypregna - 1,4 diene-3,20-dione. collected in four or six day periods and urine in one day pools. Stools, diets and urine were analyzed for nitrogen (7), phosphorus (8), calcium (9), potassium (10) and sodium (10). Blood was drawn at appropriate intervals for the determination of circulating eosinophiles and serum sodium, potassium, carbon dioxide, calcium and phosphorus. Studies of the acute effects of steroids on circulating eosinophiles over four hour periods were also done in one Addisonian and one normal subject. Four

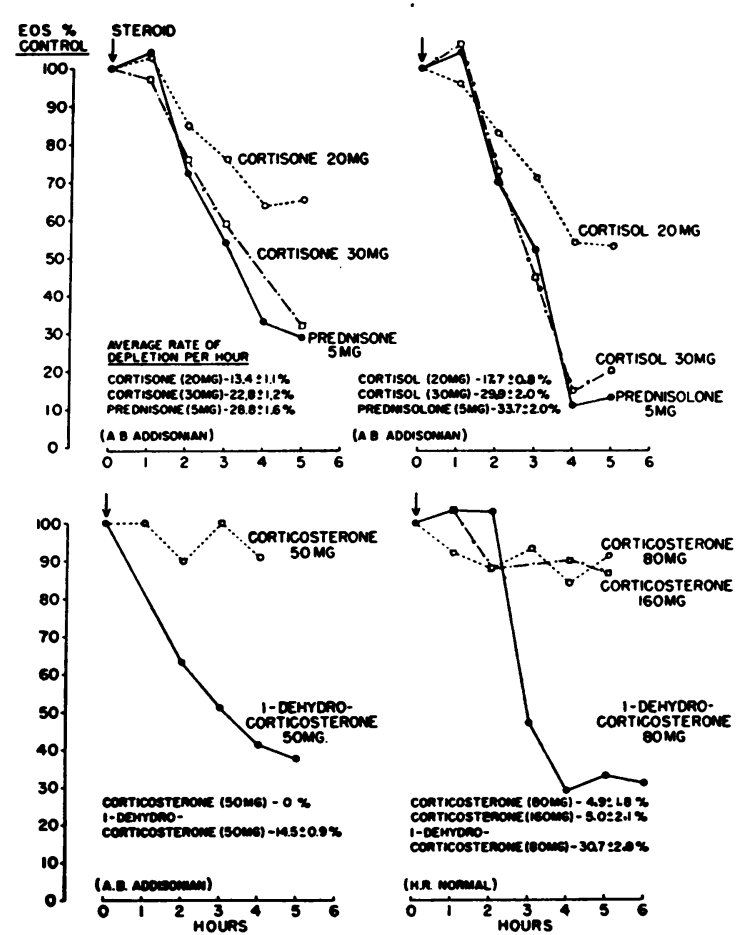

Fig. 1. The Effect of 1,4-Diene Steroids and the Parent Compounds on Circulating Eosinophiles Four Hours After InJection

Steroids were given intravenously over 10 minute periods. The average rate of depletion per hour has been determined from the slope of the linear regression (11). 


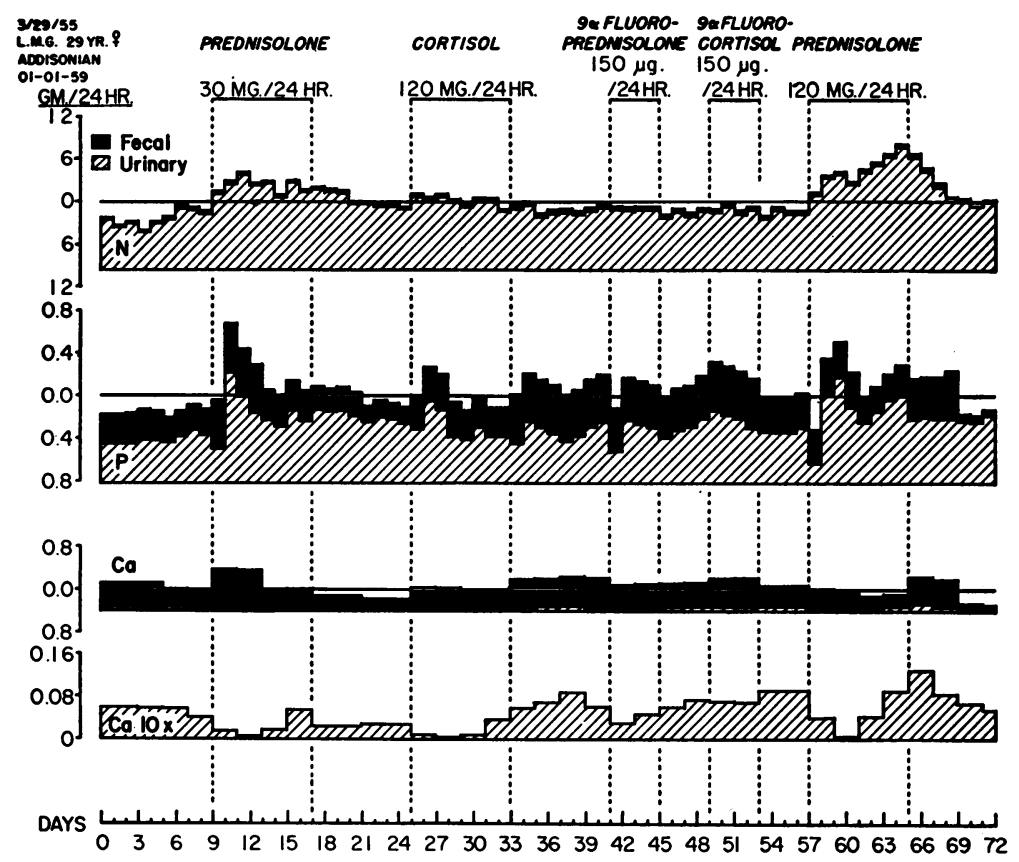

Fig. 2. The Effect of 1,4-Diene Steroids and the Parent Compounds on Nitrogen, Phosphorus and Calcium Balances in L. M. G.

Balance data in this and subsequent charts are plotted as follows: Intake is plotted downwards from the 0 line, urinary values are plotted upwards from the intake line, and fecal values are superimposed on them. Thus, positive balance is indicated by a clear area below the 0 line and negative balance by a shaded area above it.

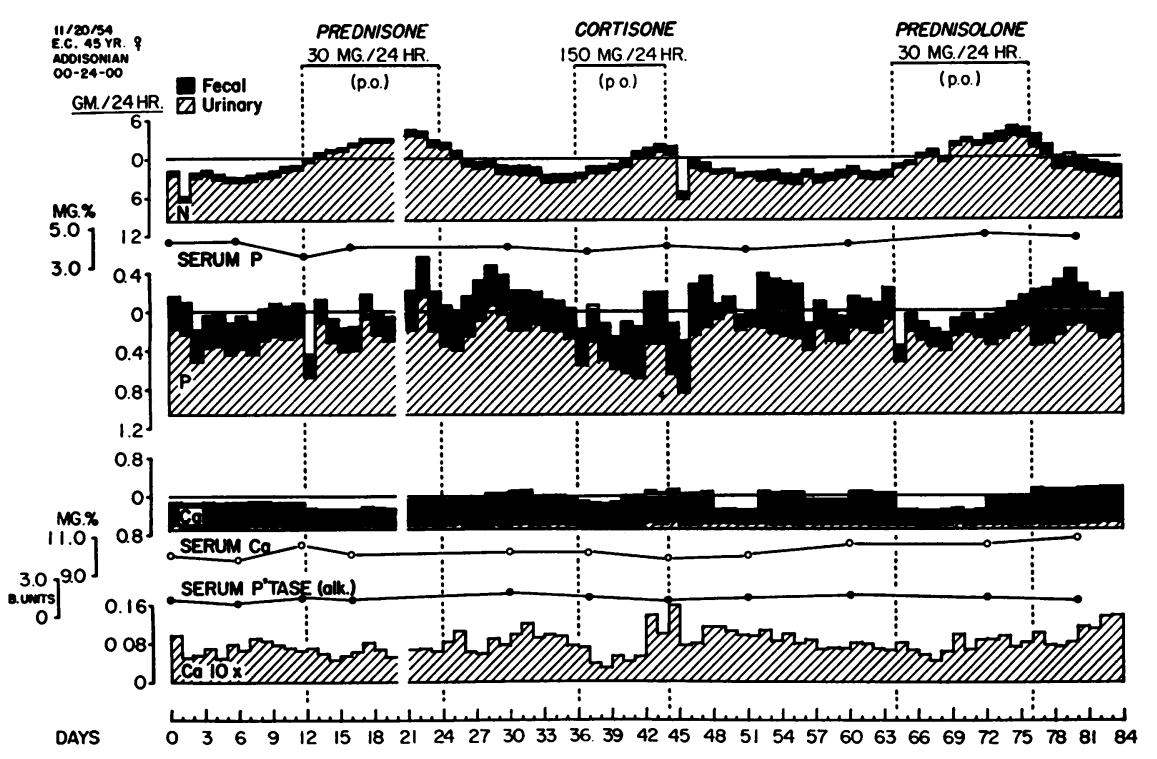

Fig. 3. The Effect of 1,4-Diene Steroids and the Parent Compounds on Nitrogen, Phosphorus and Calcium Balances, Serum Phosphorus, Calcium and Alkaline Phosphatase in E. C. 


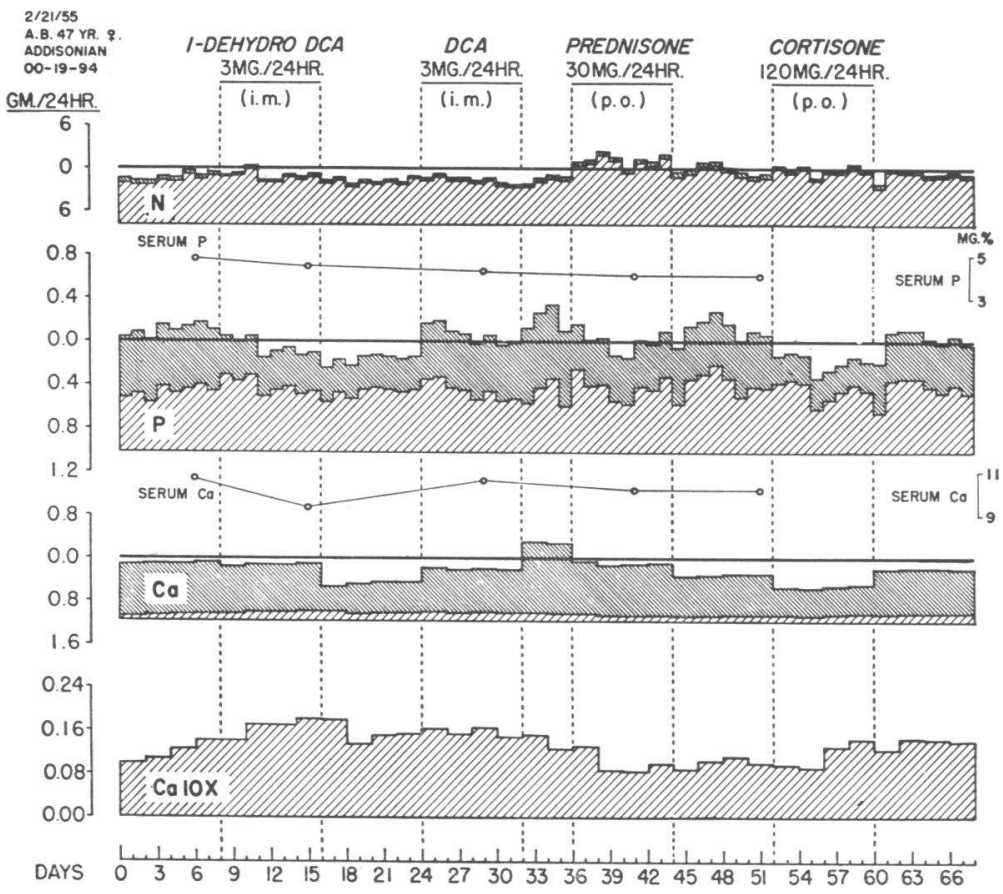

Fig. 4. The Effect of 1,4-Diene Steroids and the Parent Compounds on Nitrogen, Phosphorus and Calcium Balances, Serum Phosphorus and Calcium in A. M. B.

\section{CUMULATIVE NITROGEN EXCRETION}

IN ADDISONIAN SUBJECTS

\section{DEVMATON FROM CONTROL}
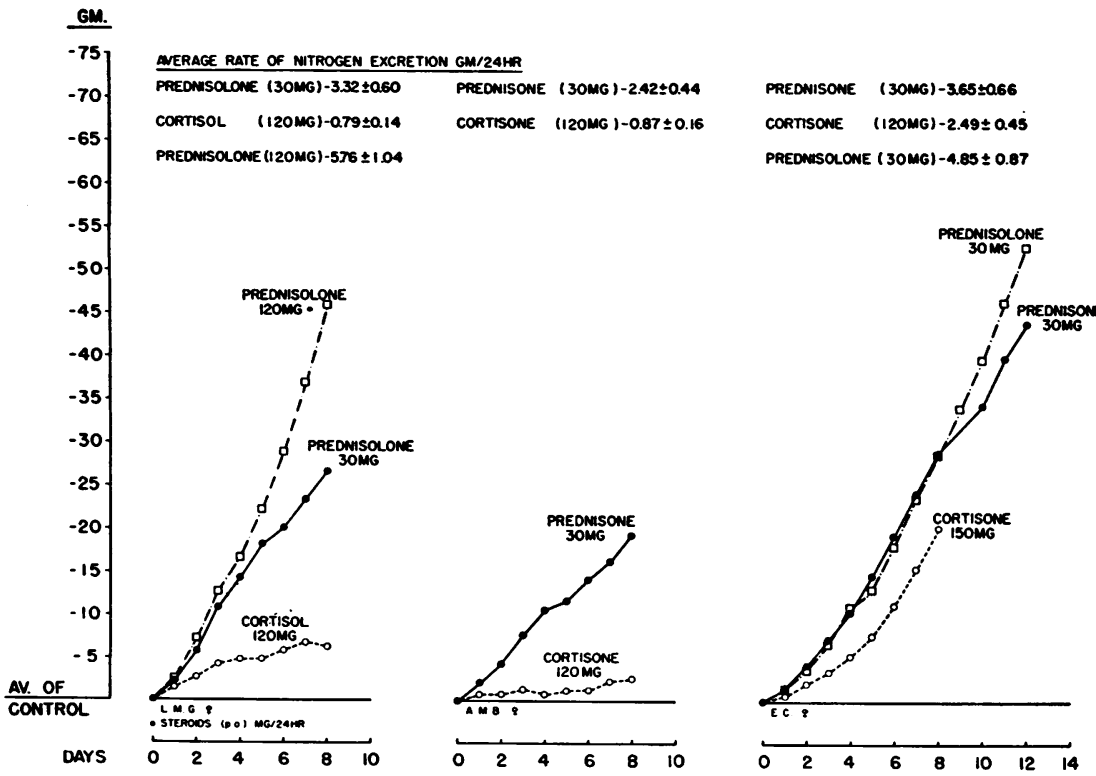

Fig. 5. The Effect of 1,4-Diene Steroids and the Parent Compounds on Nitrogen Excretion Expressed as the Mean Daily Difference Between Treatment and Control Periods

The daily deviation from control is plotted cumulatively. The daily average rate of nitrogen excretion has been determined from the slope of the linear regression (11). 


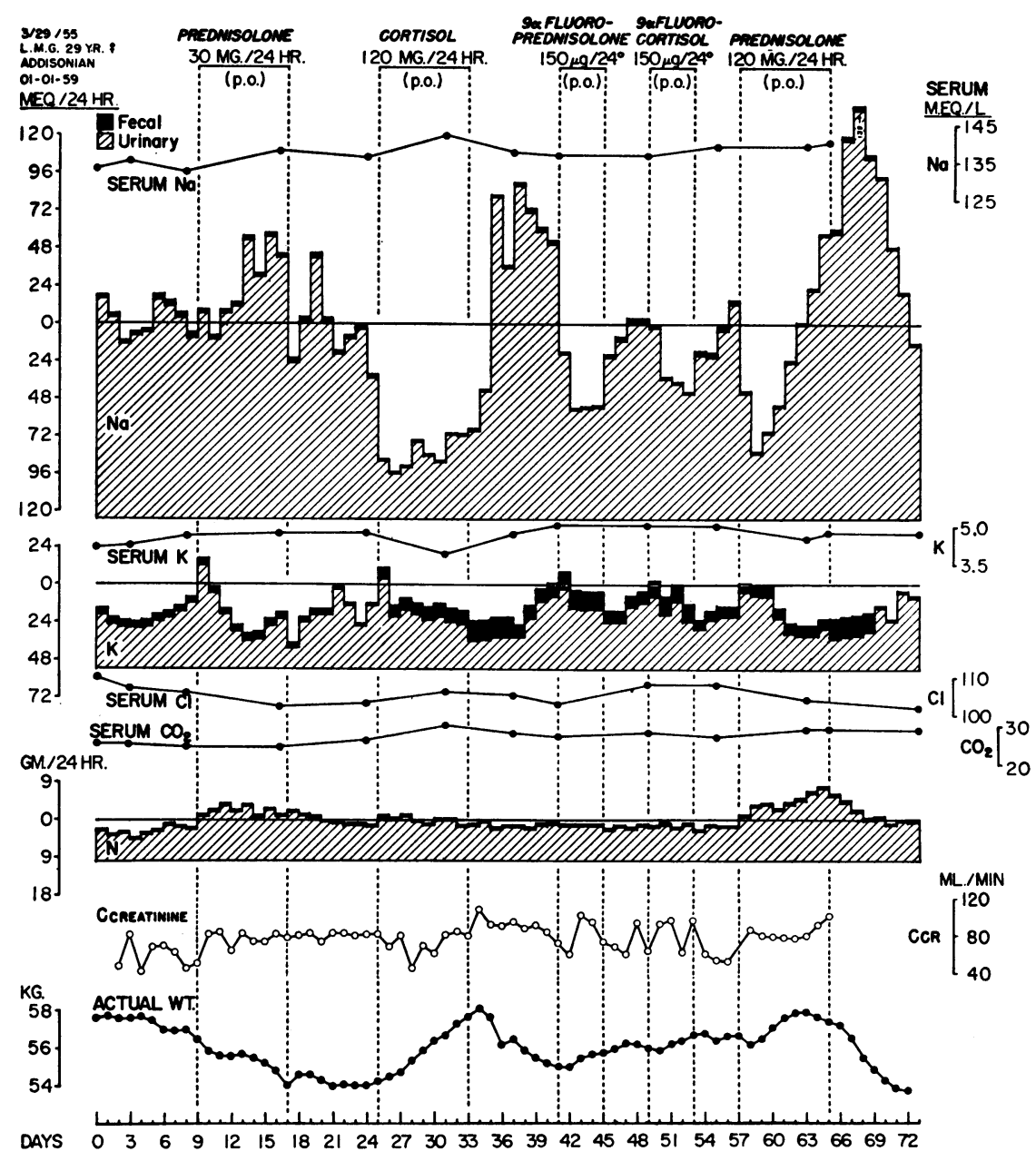

Fig. 6. The Effect of 1,4-Diene Steroids and the Parent Compounds on Sodium, Potassium and Nitrogen Balances, Serum Sodium, Potassium, Chloride, Carbon Dioxide, Creatinine Clearance and Body Weight in L. M. G.

separate pipettes were filled with blood at the control and each of five hours following the intravenous administration of the steroid and counted separately. Inulin and para-aminohippurate clearances were used as measures of glomerular filtration rate and renal plasma flow, respectively, in one subject. In the other two, 24 hour clearances of endogenous creatinine were used as an index of glomerular filtration rate. Steroids were given orally, one-quarter of the daily dose every six hours.

\section{RESULTS}

The results are shown graphically in Figures 1 through 13.

Inasmuch as anti-inflammatory activity is found in association with eosinopenic and anti-anabolic or catabolic activity, the effects of these steroids on eosinophiles and on the constituents of protoplasm were examined.

\section{The eosinopenic effect}

Figure 1 shows the effects of single doses of steroids administered intravenously on circulating eosinophiles. The 1,4-diene steroids were four to six times as active as the parent compounds. $^{2}$ This was so for 1-dehydrocorticosterone

2 It was on the basis of these studies that the factor "4" was originally chosen for the comparative study of anti-inflammatory activities of prednisone, prednisolone and their parent compounds in rheumatoid arthritis. In fact (vide infra), a higher factor is probably more correct. 


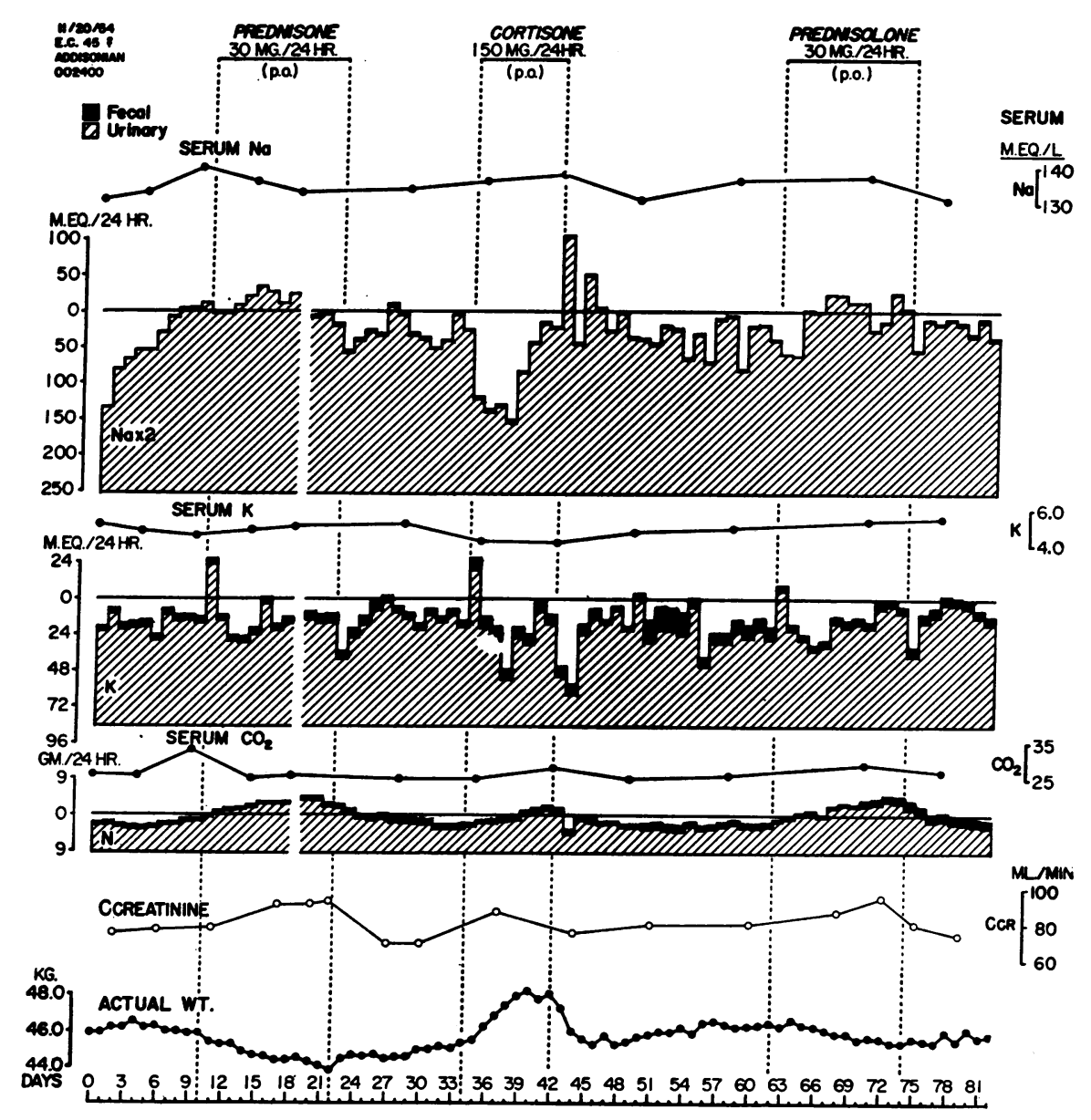

Fig. 7. The Effect of 1,4-Diene Steroids and the Parent Compounds on Sodium, Potassium and Nitrogen Balances, Serum Sodium, Potassium, Carbon Dioxide, Creatinine Clearance and Body Weight in E. C.

which lacks a hydroxyl group at carbon 17 as well as for prednisone and prednisolone which possess it.

\section{Nitrogen metabolism}

Prednisone and prednisolone, in doses of 30 mg. a day, caused an increase in urinary nitrogen excretion and a negative nitrogen balance (Figures 2 through 4 ). The loss of nitrogen with 30 $\mathrm{mg}$. of the 1,4-diene steroids was considerably greater than that with the parent compounds, cortisone and cortisol, at doses four or five times as large. These results are summarized in Figure 5. As judged from the effects on nitrogen metabolism, prednisone and prednisolone, administered orally, appeared to be 10 to 17 times [parallel line assay method (11)] as active as the parent steroids.

\section{Phosphorus metabolism}

Prednisone and prednisolone, in doses of $30 \mathrm{mg}$. a day, had little effect on phosphorus metabolism. In all cases but one there was a transient fall in urinary phosphorus on the first day of therapy and a transient rise on the second day. In the remaining case (Figure 4) urinary phosphorus rose on the first day. In all cases but one urinary phosphorus fell after therapy was stopped. In no case was there a loss of phosphorus commensurate $[\mathrm{N}: \mathrm{P}=0.068 \mathrm{Gm}$. per $\mathrm{Gm}$. (12)] with the loss of nitrogen. The effects of the 1,4-diene steroids on phosphorus were quite comparable with those 


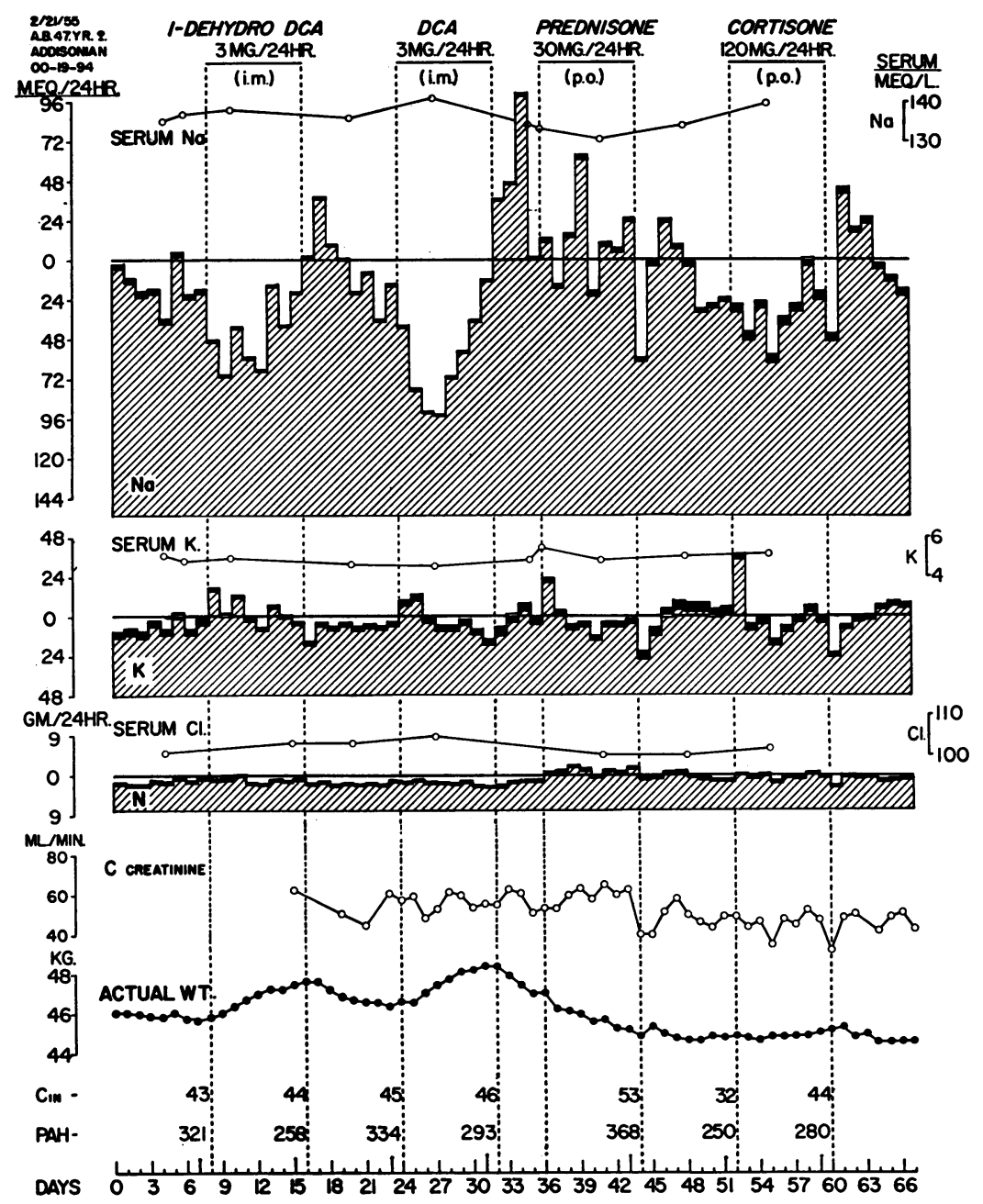

Fig. 8. The Effect of 1,4-Diene Steroids and the Parent Compounds on Sodium, Potassium, and Nitrogen Balances, Serum Sodium, Potassium, Chloride, Body Weight, Creatinine Clearance, Inulin Clearance and Para-aminohippurate Clearance in A. M. B.

of the parent compounds at doses four or five times as great. Wide fluctuations in fecal phosphorus, apparently not related to steroid thereapy, induced corresponding fluctuations in phosphorus balance and made it difficult to interpret. A relative retention of phosphorus during steroid-induced nitrogen loss has been attributed to concomitant glycogen formation (13). On the other hand, the phenomenon may represent the loss of relatively phosphorus-poor protein.

\section{Calcium metabolism}

With prednisone and prednisolone, in doses of $30 \mathrm{mg}$. a day, there was a transient fall of urinary calcium in two cases (Figures 2 and 4) and no change in the other (Figure 3 ). Fecal calcium was lower than that in the control periods during three of the four periods studied at this dose. With cortisone and cortisol, in doses four to five times as large, there was a fall of urinary calcium. This was accompanied by sodium retention and weight gain. There was a similar fall of urinary calicum, with sodium retention, with prednisolone at a dose of $120 \mathrm{mg}$. a day (Figure 2). The calcium retention with cortisone, cortisol and with the $120 \mathrm{mg}$. dosage of prednisolone did not persist throughout treatment, the "escape" therefrom closely paralleling that of sodium (vide infra). 
STUDIES WITH A NEW SERIES OF 1,4-DIENE STEROIDS. I.

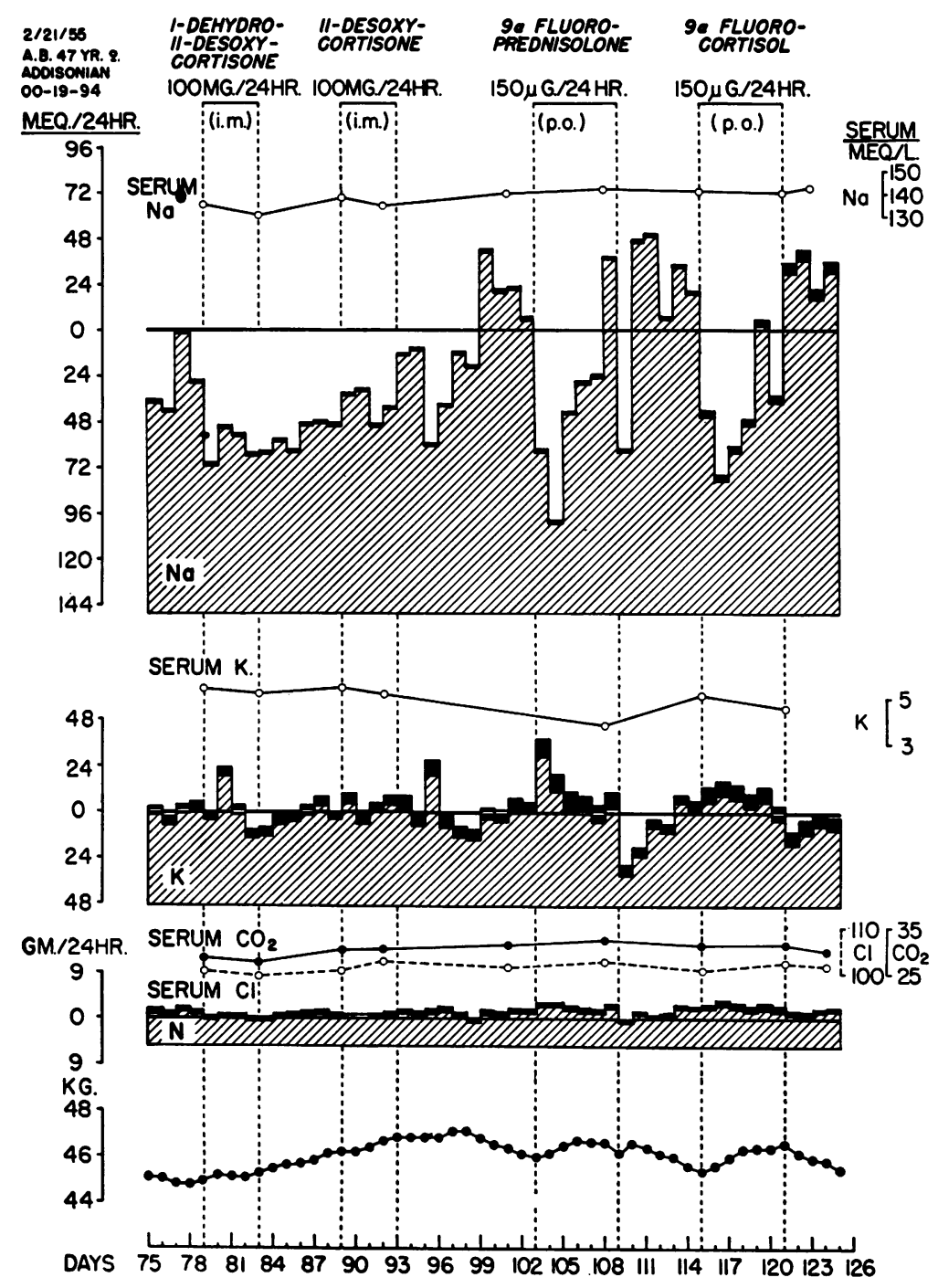

Fig. 9. The EfFect of 1-Dehydro-11-Desoxycortisone, 9 $\alpha$-Fluoroprednisolone and the Parent Compounds on Sodium, Potassium and Nitrogen Balances, Serum Sodium, Potassium, Carbon Dioxide, ChloRIDE AND Body WeIght IN A. M. B.

The amounts of calcium gained and lost were approximately those normally found in the volumes of extracellular fluid (ECF) gained and lost concomitantly ( $\mathrm{Ca}: \mathrm{Na}=0.36 \mathrm{mg}$. per $\mathrm{mEq}$. in $\mathrm{ECF})$.

\section{Potassium metabolism}

Prednisone and prednisolone produced a transient increase of urinary potassium, with negative balance, on the first day of therapy: With $120 \mathrm{mg}$. of prednisolone a day this effect persisted for three days. When treatment was stopped, there was a transient decrease of urinary potassium, with positive balance, for one or two days. The same changes occurred with cortisone and cortisol at four to five times the dose. The results are summarized in Figure 12. These changes in potassium balance were not accompanied by commensurate $[\mathrm{N}: \mathrm{K}=2.7 \mathrm{mEq}$. per $\mathrm{Gm}$. (12)] changes in nitrogen balance and in most instances precede by a day corresponding changes in urinary phosphorus. 


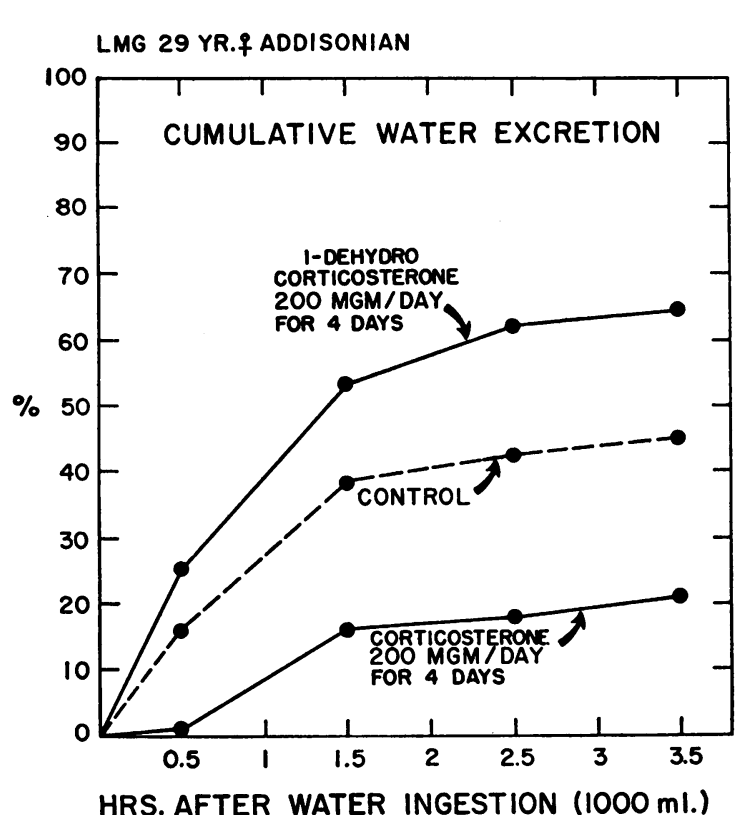

Fig. 10. The EFfEct OF 1-Dehydrocorticosterone and the Parent Compound on Cumulative Water EXCRETION FOLLOWING a Standard Water LOAd IN L. M. G.

\section{$V I$. Sodium metabolism}

With prednisone and prednisolone, in doses of $30 \mathrm{mg}$. a day, there was a slight (Figures 7 and 8 ) to moderate (Figure 6 ) rise in urinary sodium, with negative sodium balance. With cortisone and cortisol, at doses four to five times as large, there was slight (Figure 8) to marked (Figures 6 and 7) sodium retention. In the experiment with cortisone (Figure 7) there was "escape" from sodium retention during therapy. With prednisolone, at a dose of $120 \mathrm{mg}$. a day (Figure 6 ), there was early sodium retention followed by "escape" such that there was substantial sodium loss during the last two days of therapy. Similar results were obtained by other workers (4-6).

With 1-dehydrodesoxycorticosterone acetate (1dehydro-DCA), at a dose of $3 \mathrm{mg}$. a day (Figure 8 ), there was moderate sodium retention. With desoxycorticosterone acetate (DCA), at the same dosage, there was the same degree of sodium retention.

With $9 \alpha$-fluoroprednisolone, at a dosage of 150 $\mu g$. a day (Figures 6 and 9), there was moderate sodium retention in two subjects: With $9 \alpha$-fluorocortisol, at the same dose, there was the same degree of sodium retention.

\section{Glomerular filtration rate (GFR)}

With prednisone and prednisolone, in doses of $30 \mathrm{mg}$. a day, the inulin clearance rose in A. B. (Figure 8), and the endogenous creatinine clearance rose in E. C..(Figure 7) and in L. M. B. (Figure 6). With cortisone and cortisol, in doses four or five times as large, the corresponding inulin and creatinine clearances rose in A. B. and in E. C., but not in L. M. G. The fluctuations in 24 hour creatinine clearances were such as to render the changes of questionable statistical significance; the observations on inulin clearance with prednisone and cortisone were limited in number. Figure 13 shows results of therapy with prednisone and prednisolone, 60 to $70 \mathrm{mg}$. a day, on inulin clearance in four other subjects with normal renal and adrenal cortical function: For two of them the effect of cortisone and cortisol, at doses four times as large, is also shown. With both types of treatment comparable rises were produced.

\section{DISCUSSION}

The results indicate that the introduction of a double bond at position 1-2 increases the eosinopenic and anti-anabolic or catabolic activity of steroids originally possessing these properties. These properties are always associated with oxygen functions at carbon 11 and carbon 17 . When these are not present, eosinopenic and anti-analbolic or catabolic properties are absent.

With the 1-2 double bond in the absence of an oxygen function at carbon 11 (1-dehydro-11desoxycortisol, see Figure 9), no anti-anabolic or
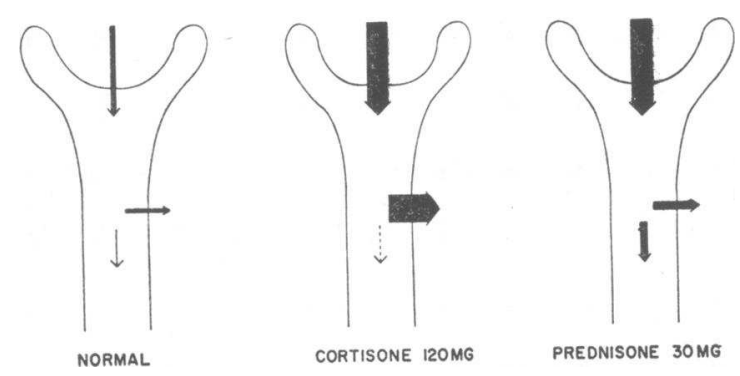

Fig. 11. Schema to Illustrate the Different EfFects of a 1,4-Diene Steroid (Prednisone) and the Parent Compound (Cortisone) on Renal Function

The arrows represent sodium, the upper one representing filtered sodium, the middle one reabsorbed sodium and the lower one urinary sodium. 
catabolic activity was found. With the 1-2 double bond in the absence of an oxygen function at carbon 17 (1-dehydrocorticosterone, see Figure 1), eosinopenic activity appeared in a steroid whose parent compound lacked this property. The data in Figure 10 suggest that corticosterone also acquired the ability to promote a water diuresis with the introduction of a 1-2 double bond; this property is associated with the anti-anabolic or catabolic activity of steroids. It thus appears that enhancement of anti-anabolic or catabolic (and anti-inflammatory) activity by 1,2-dehydrogenation depends upon the presence of an oxygen atom at carbon 11.
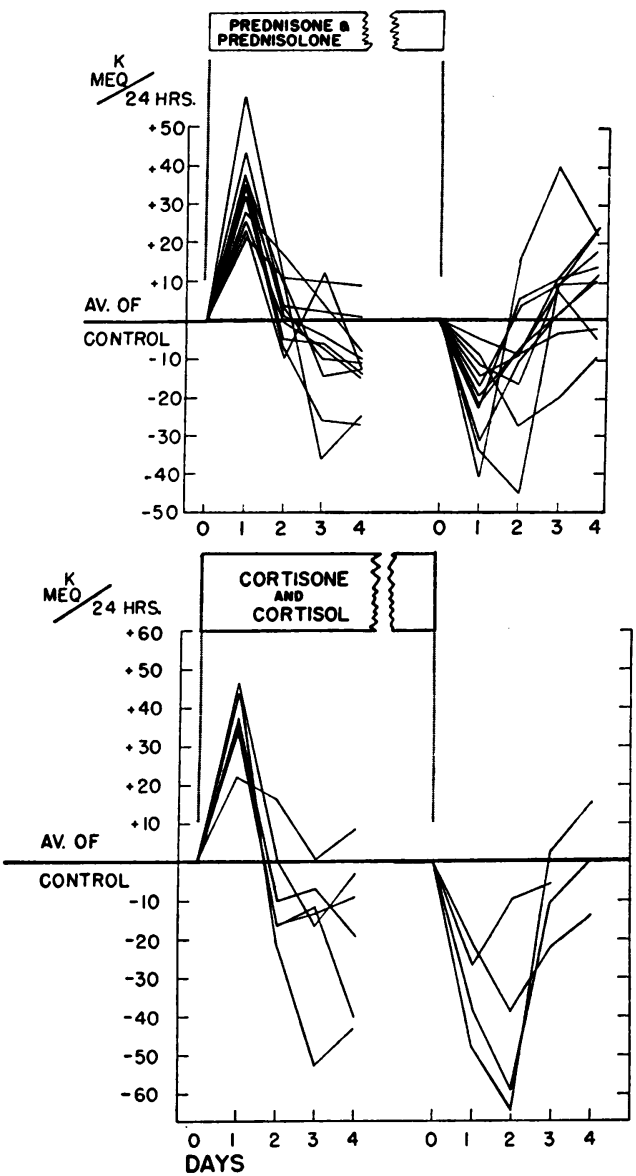

Fig. 12. The Effect of 1,4-Diene Steroids and the Parent Compounds on Urinary Potassium, Expressed as a Deviation from the Average of That of the Control Periods of the First four Days on and the First Four Days After Treatment

The data include all the studies reported by the present paper and studies in normal subjects.

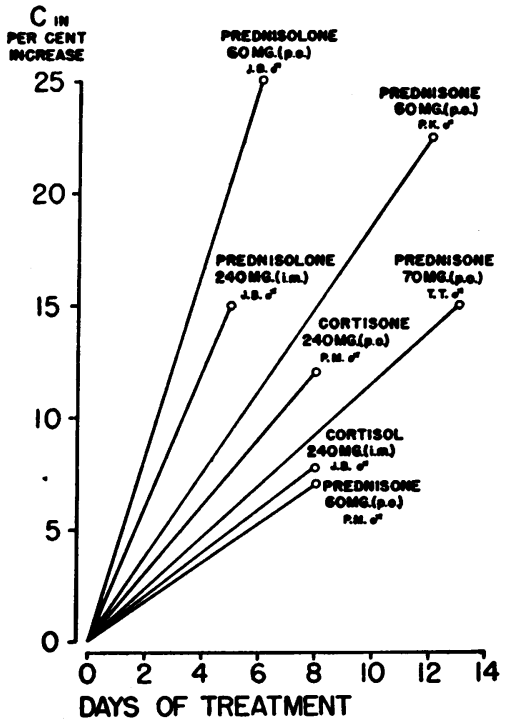

Fig. 13. The Effect of 1,4-Diene Steroids and the Parent Compounds on Inulin Clearance in Four Subjects with Normal Renal and Adrenal Cortical Function

The property of anti-anabolic or catabolic steroids to increase the glomerular filtration rate appeared to be enhanced in the 1,2-dehydrogenated steroids in parallel with the enhancement of antianabolic or catabolic activity itself.

Whereas 1,2-dehydrogenation thus affects the properties of 11,17-oxygenated steroids quantitatively by increasing anti-anabolic or catabolic activity, it appears to affect them qualitatively as regards sodium metabolism. Whereas sodium retention generally occurs with the parent compounds, cortisone and cortisol, sodium loss is regularly seen with the 1,4-diene derivatives, prednisone and prednisolone.

To explain the difference in the effects on sodium metabolism it is not necessary to postulate that unsaturation at carbon 1-2 affects tubular sodium transport directly: In the comparison of DCA with 1-dehydro-DCA no such effect was apparent. The sodium loss produced with the 1 , 4-dienes is more likely a result of the increase in glomerular filtration rate, and thus of tubular sodium "load," which these steroids produce. This effect is correlated with anti-anabolic or catabolic activity of steroids (14). Since 1,2dehydrogenation enhances this type of activity, it could confer on a steroid the ability to cause 
sodium diuresis without having any effect on its ability to potentiate tubular sodium transport. Figure 11 represents this concept diagrammatically. If prednisone, at a dosage of $30 \mathrm{mg}$., can increase glomerular filtration rate as much as cortisone, at a dosage of $120 \mathrm{mg}$. (as our data suggest), it can produce sodium loss if the effect on tubular transport, milligram for milligram, is the same in the two steroids. When $9 \alpha$-fluoroprednisolone was compared with $9 \alpha$-fluorocortisol, in doses too small to affect glomerular filtration rate (Figures 6 and 9), the effects on sodium balance were the same.

\section{SUMMARY AND CONCLUSIONS}

The effect of unsaturation by 1,2-dehydrogenation on the activity of 21-carbon steroids was explored with balance and renal studies in three patients with Addison's disease. Unsaturation at carbon 1-2 resulted in an increase in anti-anabolic or catabolic properties in those steroids with oxygen at carbons 11 and 17 (for example, cortisone and cortisol) and in the appearance of such properties in a steroid with oxygen at carbon 11 but not at carbon 17 (corticosterone).

Unsaturation at carbon 1-2 resulted in a loss of sodium-retaining properties in those steroids in which it enhanced anti-anabolic or catabolic properties, when given in doses large enough to increase the glomerular filtration rate; this loss of sodium-retaining properties is ascribed to the "glomerulotubular" imbalance so induced.

\section{REFERENCES}

1. Pechet, M. M. The metabolic effects of metacortandracin and metacortandralone in man: A new series of $\Delta^{1,4}$-diene steroids. J. clin. Invest. 1955, 34, 913.

2. Herzog, H. L., Nobile, A., Tolksdorf, S., Charney, W., Hershberg, E. B., Perlman, P. L., and Pechet, M. M. New anti-arthritic steroids. Science 1955, $121,176$.
3. Bunim, J. J., Pechet, M. M., and Bollet, A. J. Studies on metacortandralone and metacortandracin in rheumatoid arthritis. J. Amer. med. Ass. 1955, 157, 311.

4. Gjфrup, S., Killmann, S. A., and Thaysen, J. H. The metabolic effects of prednisone in patients with rheumatoid arthritis. Acta rheum. scand. 1956, 2, 223.

5. Nabarro, J. D. N., Stewart, J. S., and Walker, G. Clinical and metabolic effects of prednisone. Lancet $1955,2,993$.

6. Rosen, P. S., Carter, A. J., Dauphinee, J. A., Gornall, A. G., and Ogryzlo, M. A. Metabolic effects of metacortandracin (prednisone) and metacortandralone (prednisolone): Comparison with ACTH, cortisone, hydrocortisone, and $9 \alpha$-fluorohydrocortisone. Canad. med. Ass. J. 1956, 74, 501.

7. Folin, O. Laboratory Manual of Biological Chemistry, 5th ed. New York, Appleton-Century Co., Inc., 1934.

8. Fiske, C. H., and Subbarow, Y. The colorimetric determination of phosphorus. J. biol. Chem. 1925, $66,375$.

9. Fiske, C. H., and Logan, M. A. Determination of calcium by alkalimetric titration. II. Precipitation of calcium in the presence of magnesium, phosphate, and sulfate, with applications to analysis of urine. J. biol. Chem. 1931, 93, 211.

10. Berry, J. W., Chappell, D. G., and Barnes, R. B. Improved method of flame photometry. Industr. engin. Chem. (Analyt. Ed.) 1946, 18, 19.

11. Finney, D. J. Statistical Method in Biological Assay. New York, Hafner Publishing Co., 1952.

12. Reifenstein, E. C., Jr., Albright, F., and Wells, S. L. The accumulation, interpretation, and presentation of data pertaining to metabolic balances, notably those of calicum, phosphorus, and nitrogen. J. clin. Endocr. 1945, 5, 367.

13. Bartter, F. C., Fourman, P., Albright, F., Forbes, A. P., Jefferies, W. M., Griswold, G., Dempsey, E., Bryant, D., and Carroll, E. The effect of adrenocorticotropic hormone in panhypopituitarism. J. clin. Invest. 1950, 29, 950.

14. Liddle, G. W., Pechet, M .M., and Bartter, F. C. Enhancement of biological activities of corticosteroids by substitution of halogen atoms in $9 \alpha$ position. Science 1954, 120, 496. 